4

5

\title{
Title: Formation temperatures of thermogenic and biogenic methane
}

\author{
Authors: D.A. Stolper ${ }^{\mathrm{a} 1}$, M. Lawson ${ }^{\mathrm{b}}$, C.L. Davis ${ }^{\mathrm{b}}$, A.A. Ferreira ${ }^{\mathrm{c}}$, E.V. Santos Neto ${ }^{\mathrm{c}}$, G.S.

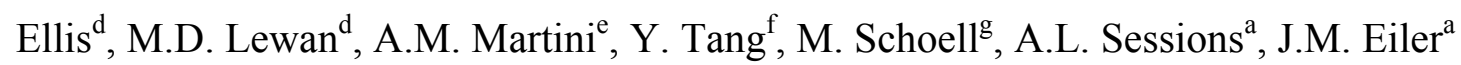 \\ Affiliations: ${ }^{a}$ Division of Geological and Planetary Sciences, California Institute of Technology, Pasadena, CA, USA \\ ${ }^{b}$ ExxonMobil Upstream Research Company, Houston, TX, USA \\ ${ }^{c}$ Division of Geochemistry, Petrobras Research and Development Center (CENPES), Rio de Janeiro, RJ, Brazil \\ ${ }^{d}$ U.S. Geological Survey, Denver Federal Center, Denver, CO, USA \\ ${ }^{e}$ Department of Geology, Amherst College, Amherst, MA, USA \\ ${ }^{f}$ Power, Environmental, and Energy Research Institute, Covina, CA USA \\ ${ }^{g}$ GasConsult International Inc, Berkeley, CA, USA
}

3

For submission to Science

Abstract: Methane is an important greenhouse gas and energy resource generated dominantly by methanogens at low temperatures and through the breakdown of organic molecules at high temperatures. However, methane formation temperatures in nature are often poorly constrained.

We measured formation temperatures of thermogenic and biogenic methane using a 'clumped isotope' technique. Thermogenic gases yield formation temperatures between $157-221^{\circ} \mathrm{C}$, within the nominal gas window, and biogenic gases yield formation temperatures consistent with their known lower formation temperatures $\left(<50^{\circ} \mathrm{C}\right)$. In systems where gases have migrated and other proxies for gas generation temperature yield ambiguous results, methane clumped-isotope

\footnotetext{
${ }^{1}$ Corresponding author: 1200 E. California Blvd, Pasadena, CA 91125, dstolper@ caltech.edu, 626-395-3753
} 
25 models.

Main Text: The environmental conditions, rates, and mechanisms of methane formation

29 are critical to understanding the carbon cycle and for predicting where economically substantial

30 amounts of methane form. Conventional models of thermogenic methane formation predict that:

31 (i) gas formation is kinetically controlled by time, temperature, and organic matter composition

32 (1); (ii) gases co-generated with oil form below $\sim 150-160^{\circ} \mathrm{C}(2-4)$; and (iii) gases created from

33 the breakdown (cracking) of oil or refractory kerogen form above $\sim 150-160^{\circ} \mathrm{C}(2-4)$. Microbially

34 produced (biogenic) methane in nature is thought to form mostly below $\sim 80^{\circ} \mathrm{C}(5,6)$.

Our understanding of the kinetics of thermogenic methane formation is dominantly

constrained by extrapolating kinetic parameters from high-temperature $\left(\sim>300^{\circ} \mathrm{C}\right)$ laboratory

37 experiments to lower temperature $\left(\sim 100-200^{\circ} \mathrm{C}\right)$, geologically relevant conditions $(7)$. These

38 experiments are sensitive to heating rates (7) and the activity of water $(1,7-10)$, minerals (1), and

39 transition metals (11); the observed range of derived kinetic parameters can result in divergent

40 predictions for natural methane formation temperatures $(1,10)$. Additionally, many thermogenic

41 gases have migrated from their source to a reservoir $(3,12-14)$. Although these migrated gases

42 dominate the datasets used to calibrate empirical models of thermogenic methane formation (3,

43 13-15), the ability to understand their thermal histories, and thus accurately calibrate models, is

44 hampered by: (i) a lack of independent constraints on the thermal histories of the source and

45 reservoir rocks and the timing of gas migration, and (ii) the possibility that a reservoir contains a

46 mixture of gases from different sources. Finally, biogenic gases are produced ubiquitously in 
47 near-surface sedimentary environments $(6,16)$ and can co-mingle with thermogenic gases (17).

48 Despite the many empirical tools used to distinguish biogenic from thermogenic gases (18),

49 identifying the sources and quantifying relative contributions of biogenic and thermogenic gases

50 in nature remains challenging (17).

$51 \quad$ We measured multiply substituted ('clumped') isotope temperatures of methane (19)

52 generated via the experimental pyrolysis of larger organic molecules and sampled from natural

53 thermogenic deposits of the Haynesville Shale (USA), Marcellus Shale (USA) and Potiguar

54 Basin (Brazil) (20), and from natural systems with methanogens from the Gulf of Mexico and

55 Antrim Shale (USA). We quantified the abundance of both ${ }^{13} \mathrm{CH}_{3} \mathrm{D}$ and ${ }^{12} \mathrm{CH}_{2} \mathrm{D}_{2}$, two clumped

56 isotopologues of methane, relative to a random isotopic distribution via the parameter $\Delta_{18}(20)$.

57 For isotopically equilibrated systems, $\Delta_{18}$ values are a function of temperature, dependent only

58 on the isotopic composition of methane, and thus can be used to calculate methane formation

59 temperatures (Fig. 1A; 19, 20, 21). It was not obvious prior to this work what $\Delta_{18}$-based

60 temperatures of natural samples would mean, in part because conventional models assume that

61 methane forms via kinetically (as opposed to equilibrium) controlled reactions (1-3, 8, 22-24).

62 We generated methane from larger hydrocarbon molecules at constant temperatures in

63 two experiments: pyrolysis of propane at $600^{\circ} \mathrm{C}(20)$ and closed-system hydrous pyrolysis $(7,9)$

64 of organic matter at $360^{\circ} \mathrm{C}(20)$. For both, $\Delta_{18}$ temperatures are within $2 \sigma$ of experimental

65 temperatures (Fig. 1A; Table S1). This supports the suggestion in (19) that measured $\Delta_{18}$-based

66 temperatures of thermogenic methane could record formation temperatures.

67 We next examined thermogenic shale gases from the Haynesville Shale (25). In shale-gas

68 systems, the shale is both the source and reservoir for generated hydrocarbons (26), thus

69 minimizing complications associated with gas migration for our interpretations. Geological 
70 constraints indicate that the Haynesville Shale has undergone minimal uplift $(\sim<0.5 \mathrm{~km} ; 20)$

71 since reaching maximum burial temperatures (modeled to currently be within $5-17^{\circ} \mathrm{C}$ of

72 maximum burial temperatures; Tables S2,3;20). Measured $\Delta_{18}$ temperatures range from 169-

$73207^{\circ} \mathrm{C}$, overlapping, within uncertainty, current reservoir temperatures $\left(163-190^{\circ} \mathrm{C}\right.$; Fig. 1A,B;

74 Table S2). We also compared the $\Delta_{18}$ temperatures to independently calculated gas-formation

75 temperatures using the generation kinetics of Burnham (20, 27). Modeled average gas-formation

76 temperatures from secondary oil breakdown range from $168-175^{\circ} \mathrm{C}$ (Table S3; 20). The modeled

77 temperatures are lower than, but within uncertainty of, measured $\Delta_{18}$ temperatures (Table S2).

78 This difference likely reflects the fact that the model calculates an average formation temperature

79 that includes all hydrocarbon gases (i.e., $\mathrm{C}_{1-5}$ alkanes), but the types of experiments used to

80 calibrate the model generate methane at a higher average temperature than other hydrocarbon

81 gases (28). Thus, average methane formation temperatures should be higher than those modeled

82 for average hydrocarbon gas-formation temperatures. Consequently, $\Delta_{18}$ temperatures are

83 consistent with expected methane formation temperatures. However, in this case, it is also

84 possible that methane re-equilibrated from some other, initial $\Delta_{18}$ value to one consistent with its

85 subsequent storage temperatures.

86 Next, we considered shale gases from uplifted rocks $(>3 \mathrm{~km}$ of uplift after maximum

87 burial; 20) in the Marcellus Shale (29), which reached modeled maximum burial temperatures of

$88 \quad 183-219^{\circ} \mathrm{C}$, but today are $60-70^{\circ} \mathrm{C}$ (Tables $\mathrm{S} 2,3 ; 20$ ). This system allows us to examine the

89 effects of gradual cooling and long-term storage at temperatures colder than methane formation

90 temperatures on $\Delta_{18}$ values. Samples yield $\Delta_{18}$ temperatures from $179-207^{\circ} \mathrm{C}$, overlapping those

91 for the Haynesville Shale and hotter than current reservoir temperatures (Fig. 1B). Modeled

92 formation temperatures (using the Burnham kinetics as above; 27) are $171-173^{\circ} \mathrm{C}$ (Table S3) - 
93 the modeled temperatures are again slightly lower than the measured $\Delta_{18}$ temperatures (for

94 reasons discussed above), but the two are within analytical uncertainty (Table S2). We conclude

95 that $\Delta_{18}$ temperatures of Marcellus Shale methane are indistinguishable from independent

96 expectations regarding methane formation temperatures and were not noticeably influenced by

97 later cooling.

98 We also examined thermogenic gases from the southwestern sector of the Potiguar Basin

99 (30) that migrated from deeper sources to shallower reservoirs (31). Here, measured $\Delta_{18}$

100 temperatures range from $157-221^{\circ} \mathrm{C}$ and exceed current reservoir temperatures $\left(66-106^{\circ} \mathrm{C}\right.$; Table

101 S2). This is consistent with vertical migration of gases from hotter sources to cooler reservoirs

102 (3). We note that some source rocks in the Potiguar Basin near where samples were collected

103 have experienced sufficient burial temperatures to reach a vitrinite reflectance of $2.7 \%$, within

104 the range observed for the Haynesville and Marcellus shale gas source rocks (1.7-3.1\%; Table

105 S3) and consistent with the high-temperature $\left(>150-160^{\circ} \mathrm{C} ; 2-4\right)$ 'dry gas zone' in which oil is

106 hypothesized to crack to gas (3). Thus, the $\Delta_{18}$ temperatures from Potiguar Basin methane (157-

$107221^{\circ} \mathrm{C}$ ) are compatible with the thermal history of some source rocks in the region. Additionally,

108 a positive correlation exists between the $\Delta_{18}$ temperatures and $\delta^{13} \mathrm{C}$ values (32) of Potiguar Basin

109 gases (Fig. $2 ; p$-value $=0.008)$ with a slope, $5.3^{\circ} \mathrm{C} / \% 0( \pm 2.2 ; 1 \sigma)$, within error of some theoretical

110 estimates, $8.8^{\circ} \mathrm{C} / \% 0(20,22)$ and $9.4^{\circ} \mathrm{C} / \% 0(20,23)$. This relationship is expected because earlier-

111 generated methane is thought to form at lower temperatures with lower $\delta^{13} \mathrm{C}$ values than methane

112 formed later at higher temperatures $(2,3,15,23)$. The Potiguar Basin samples raise the issue that

113 mixing of gases with differing $\delta^{13} \mathrm{C}$ and $\delta \mathrm{D}$ values can result in $\Delta_{18}$ values that are not simply

114 weighted averages of the endmembers $(19,20)$. However, in this specific case (and for the shale

115 gases), $\delta^{13} \mathrm{C}$ and $\delta \mathrm{D}$ values do not span a sufficiently large range for mixing between samples to 
116 result in $\Delta_{18}$-based temperatures different (within analytical uncertainty) from the actual average

117 formation temperatures of the mixtures (Fig. S2; 20).

118 The data discussed above are consistent with the interpretation that $\Delta_{18}$ values of

119 thermogenic methane reflect isotopic equilibrium at the temperature of methane formation and

120 that the 'closure temperature' above which $\Delta_{18}$ values can freely re-equilibrate is $\sim 200^{\circ} \mathrm{C}$ in

121 geological environments because: (i) Experimentally generated methane yields $\Delta_{18}$ values within

122 error of formation temperatures (Fig. 1A). (ii) All $\Delta_{18}$ temperatures from natural samples are

123 geologically reasonable formation temperatures $(1-4,10)$. (iii) Haynesville Shale $\Delta_{18}$

124 temperatures are within uncertainty of current and modeled maximum burial temperatures (Fig.

125 1A,B). (iv) Haynesville and Marcellus Shale $\Delta_{18}$ temperatures are within error of independently

126 modeled gas-formation temperatures. (v) Haynesville and Marcellus Shale $\Delta_{18}$ temperatures

127 overlap despite the differing thermal histories of each system (the Marcellus Shale cooled by

$128>100^{\circ} \mathrm{C}$ after gas generation). This would not be expected if $\Delta_{18}$ temperatures represent closure

129 temperatures and thus reset during cooling of the host rocks. And (vi), Potiguar Basin $\Delta_{18}$

130 temperatures and $\delta^{13} \mathrm{C}$ values are positively correlated (Fig. 2), with a slope within error of

131 theoretical predictions.

132 The agreement between the Haynesville and Marcellus Shale methane $\Delta_{18}$ temperatures

133 and modeled formation temperatures demonstrates that relatively simple gas generation models

134 are accurate when the thermal histories of the source rocks are constrained. The formation

135 temperatures of the Potiguar Basin gases are challenging to constrain with such models due to

136 gas migration, which obscures the location and timing of gas formation. Previously, these gases

137 were interpreted to have been co-generated with oils (30) and thus below $\sim 160^{\circ} \mathrm{C}(2-4)$. This

138 disagreement between our data and published interpretations inspired us to examine a range of 
139 gas-formation models (20) for the Potiguar Basin samples (Fig. 3). All models presented are in

140 common use and constrained by similar gas chemistry data (20); however many disagree with

141 each other and together predict a range of over $170^{\circ} \mathrm{C}$ for gas formation (Fig. 3). The $\Delta_{18}$

142 temperatures allow these models to be independently evaluated, rejecting some (e.g., low-

143 temperature gas generation solely from kerogen) and narrowing the permitted interpretations.

144 Specifically, methane in the Potiguar Basin could have formed via the mixing of gases produced

145 by low-temperature $\left(\sim<150-180^{\circ} \mathrm{C}\right)$ kerogen breakdown with gases generated from higher-

146 temperature $\left(\sim>150-160^{\circ} \mathrm{C}\right)$ oil breakdown, consistent with the models of (23) and (27). This

147 scenario requires a specific set of mixing components to generate the observed formation

148 temperatures, $\mathrm{C}_{1} / \Sigma \mathrm{C}_{1-5}$ values (Table S2), and correlation between $\Delta_{18}$ temperatures and methane

$149 \delta^{13} \mathrm{C}$ values. Alternatively, the model of $(10)$, which is the only model presented to incorporate

150 the importance of water in gas formation, is consistent with the $\Delta_{18}$ temperatures and $\mathrm{C}_{1} / \Sigma \mathrm{C}_{1-5}$

151 values ( $<85 \%$; Table S2) for the Potiguar Basin gases. This may indicate that water should be

152 considered in models of methane formation. Although the gas generation temperatures derived

153 from the breakdown of refractory kerogen, as in the model of (27), appear compatible with the

$154 \Delta_{18}$ temperatures (Fig. 3), this organic source dominantly generates methane (27) and thus cannot

155 be the sole source of gas to the system due to the high concentration of $\mathrm{C}_{2-5}$ alkanes in the gases

$156\left(<85 \% \mathrm{C}_{1} / \Sigma \mathrm{C}_{1-5} ;\right.$ Table S2).

157 Thus, while the addition of $\Delta_{18}$ temperatures does not provide a unique interpretation of

158 the origin of the Potiguar Basin gases, it rules out several otherwise plausible interpretations and

159 places specific constraints on the remaining models. Importantly, our results for the Potiguar

160 Basin indicate that the formation environments for methane extend to higher temperatures (and

161 presumably depths) in this system than many models of petroleum genesis predicted (Fig. 3), and 
162 supports experimental evidence that significant quantities of methane can be generated at higher

163 temperatures than sometimes appreciated (33). This requires that this basin possesses a

164 previously unsuspected 'root' that reached high temperatures at some point in its history,

165 generating high-temperature methane that ascended into shallower reservoirs. Thus, $\Delta_{18}$

166 temperatures not only constrain the conditions and mechanisms of methane formation, but also

167 provide a window into the geological and thermal histories of basins in which methane forms.

168 To examine $\Delta_{18}$-based temperatures from known low-temperature sources of methane, we

169 measured $\Delta_{18}$ values from two sources of biogenic gases produced from the biodegradation of oil

170 (Gulf of Mexico). They return $\Delta_{18}$ temperatures $\left(34 \pm 8\right.$ and $48 \pm 8^{\circ} \mathrm{C}$ ) within error of their

171 current reservoir temperatures $\left(42\right.$ and $48^{\circ} \mathrm{C}$, respectively; Fig 1A,B; Table S2). We further

172 measured two gases from the Antrim Shale, which has been interpreted as containing a mixture

173 of biogenic gases higher in $\mathrm{C}_{1} / \Sigma \mathrm{C}_{1-5}$ and thermogenic gases lower in $\mathrm{C}_{1} / \Sigma \mathrm{C}_{1-5}(17)$. The sample

174 closer to the biogenic endmember $\left(99.99 \% \mathrm{C}_{1} / \Sigma \mathrm{C}_{1-5}\right)$ returns a $\Delta_{18}$ temperature of $40^{\circ} \mathrm{C}( \pm 10$;

$1751 \sigma)$, whereas the sample interpreted here to be closer to a thermogenic endmember $(88.9 \%$

$\left.176 \mathrm{C}_{1} / \Sigma \mathrm{C}_{1-5}\right)$ returns a higher temperature of $115^{\circ} \mathrm{C}\left( \pm 12^{\circ} \mathrm{C} ; 1 \sigma\right)$. Thus, the natural biogenic gases

177 have $\Delta_{18}$ temperatures consistent with their expected formation temperatures, both as pure

178 endmembers and as dominant components of mixtures. We note that preliminary results for

179 methanogens grown in pure culture (34) indicate that they can produce methane out of internal

180 isotopic equilibrium. Nevertheless, our measurements of natural biogenic methane indicate that

181 natural environments (at least those investigated to date) permit the attainment of local

182 equilibrium.

183 These results indicate that $\Delta_{18}$ values can be used to calculate formation temperatures of

184 methane from both pure and mixed thermogenic and biogenic gas deposits and interrogate 
185 models of gas formation and geological histories of basins. Additionally, if the interpretation of $186 \Delta_{18}$-based temperatures as formation temperatures is correct, it has implications for our 187 understanding of the chemistry of thermogenic and biogenic methane formation. Specifically, it 188 requires a heretofore unrecognized step for both processes that allows $\mathrm{C}-\mathrm{H}$ bonds to equilibrate 189 during methane formation. This interpretation is unexpected because $\delta^{13} \mathrm{C}$ values of thermogenic 190 and biogenic methane are almost universally considered to be controlled by kinetic-isotope 191 effects rather than equilibrium-thermodynamic effects $(2,16,22-24,35)$. This apparent 192 contradiction can be reconciled if reacting methane precursors (e.g., methyl groups) undergo 193 local hydrogen exchange faster than the rate of net methane generation. For thermogenic gases, 194 this could occur via exchange reactions with water (36) or catalytic hydrogen exchange on 195 organic macromolecules, mineral surfaces, or transition metals (11,37). For biogenic methane, 196 reversible hydrogen exchange could occur on methane or methane precursors if the pathway for 197 methane formation is partially reversible $(35,38)$. Thus, $\Delta_{18}$ measurements may also elucidate 198 chemical and biochemical mechanisms of methane formation. 


\section{References and Notes:}

200 1. J. S. Seewald, Organic-inorganic interactions in petroleum-producing sedimentary basins.

2. C. Clayton, Carbon isotope fractionation during natural gas generation from kerogen. Mar. Petro. Geol. 8, 232 (1991).

3. J. M. Hunt, Petroleum Geochemistry and Geology. (W. H. Freeman and Company, New York, 1996), pp. 743.

4. T. Quigley, A. Mackenzie, The temperatures of oil and gas formation in the sub-surface. Nature 333, 549 (1988).

5. A. Wilhelms et al., Biodegradation of oil in uplifted basins prevented by deep-burial sterilization. Nature 411, 1034 (2001).

6. D. L. Valentine, Emerging topics in marine methane biogeochemistry. Annu. Rev. Mar. Sci.3, 147 (2011).

7. M. Lewan, T. Ruble, Comparison of petroleum generation kinetics by isothermal hydrous and nonisothermal open-system pyrolysis. Org. Geochem. 33, 1457 (2002).

8. J. Espitalie, P. Ungerer, I. Irwin, F. Marquis, Primary cracking of kerogens. Experimenting and modeling $\mathrm{C}_{1}, \mathrm{C}_{2}-\mathrm{C}_{5}, \mathrm{C}_{6}-\mathrm{C}_{15+}$ classes of hydrocarbons formed. Org. Geochem. 13, 893 (1988).

9. M. Lewan, Experiments on the role of water in petroleum formation. GCA 61, 3691 (1997).

10. J. S. Seewald, B. C. Benitez-Nelson, J. K. Whelan, Laboratory and theoretical constraints on the generation and composition of natural gas. GCA 62, 1599 (1998).

11. F. D. Mango, J. Hightower, The catalytic decomposition of petroleum into natural gas. GCA 61, 5347 (1997).

12. W. England, A. Mackenzie, D. Mann, T. Quigley, The movement and entrapment of petroleum fluids in the subsurface. J. Geol. Soc. London 144, 327 (1987).

13. L. C. Price, M. Schoell, Constraints on the origins of hydrocarbon gas from compositions of gases at their site of origin. Nature 378, 368 (1995).

14. B. P. Tissot, D. H. Welte, Petroleum formation and occurrence: A new approach to oil and gas exploration. (Springer-Verlag, Berlin, 1978), pp. 538.

15. M. Schoell, Genetic characterization of natural gases. AAPG Bulletin 67, 2225 (1983).

16. M. J. Whiticar, E. Faber, M. Schoell, Biogenic methane formation in marine and freshwater environments: $\mathrm{CO}_{2}$ reduction vs acetate fermentation-Isotope evidence. GCA 50, 693 (1986).

17. A. M. Martini, J. M. Budai, L. M. Walter, M. Schoell, Microbial generation of economic accumulations of methane within a shallow organic-rich shale. Nature 383, 155 (1996).

18. M. J. Whiticar, Carbon and hydrogen isotope systematics of bacterial formation and oxidation of methane. Chemical Geology 161, 291 (1999).

19. D. A. Stolper et al., Combined ${ }^{13} \mathrm{C}-\mathrm{D}$ and D-D clumping in methane: methods and preliminary results. GCA 126, 169 (2014).

20. Materials and methods are available on Science online.

21. J. M. Eiler, "Clumped-isotope" geochemistry - The study of naturally-occurring, multiplysubstituted isotopologues. EPSL 262, 309 (2007).

22. Y. Ni et al., Fundamental studies on kinetic isotope effect (KIE) of hydrogen isotope fractionation in natural gas systems. GCA 75, 2696 (2011). 
23. Y. Tang, J. Perry, P. Jenden, M. Schoell, Mathematical modeling of stable carbon isotope ratios in natural gases. GCA 64, 2673 (2000).

24. Y. Xiao, Modeling the kinetics and mechanisms of petroleum and natural gas generation: A first principles approach. Rev. Mineral. Geochem. 42, 383 (2001).

25. U. Hammes, H. S. Hamlin, T. E. Ewing, Geologic analysis of the Upper Jurassic Haynesville Shale in east Texas and west Louisiana. AAPG bulletin 95, 1643 (2011).

26. J. B. Curtis, Fractured shale-gas systems. AAPG bulletin 86, 1921 (2002).

27. A. Burnham, "A simple kinetic model of petroleum formation and cracking" (Lawrence Livermore National Lab, report UCID 21665, 1989).

28. P. Ungerer, State of the art of research in kinetic modelling of oil formation and expulsion. Org. Geochem. 16, 1 (1990).

29. G. G. Lash, T. Engelder, Thickness trends and sequence stratigraphy of the Middle Devonian Marcellus Formation, Appalachian Basin: Implications for Acadian foreland basin evolution. AAPG Bulletin 95, 61 (2011).

30. A. Prinzhofer, E. V. Santos Neto, A. Battani, Coupled use of carbon isotopes and noble gas isotopes in the Potiguar basin (Brazil): Fluids migration and mantle influence. Mar. Petro. Geol. 27, 1273 (2010).

31. L. Trindade, S. C. Brassell, E. V. Santos Neto, Petroleum migration and mixing in the Potiguar Basin, Brazil. AAPG Bulletin 76, 1903 (1992).

32. $\delta=\left(R / R_{\text {std }}-1\right) x 1000$ where ${ }^{13} R=\left[{ }^{13} \mathrm{C}\right] /\left[{ }^{12} \mathrm{C}\right],{ }^{D} R=[D] /[H]$, and 'std' denotes the standard to which all measurements are referenced (VPDB for carbon and VSMOW for hydrogen isotopes).

33. N. Mahlstedt, B. Horsfield, Metagenetic methane generation in gas shales I. Screening protocols using immature samples. Mar. Petro. Geol. 31, 27 (2012).

34. D. A. Stolper et al., Clumped isotopes of methane: applications to both low and high temperature natural systems. Mineralogical Magazine 78, 2393 (2014).

35. D. L. Valentine, A. Chidthaisong, A. Rice, W. S. Reeburgh, S. C. Tyler, Carbon and hydrogen isotope fractionation by moderately thermophilic methanogens. GCA 68, 1571 (2004).

36. T. Hoering, Thermal reactions of kerogen with added water, heavy water and pure organic substances. Org. Geochem. 5, 267 (1984).

37. F. D. Mango, J. Hightower, A. T. James, Role of transition-metal catalysis in the formation of natural gas. Nature 368, 536 (1994).

38. S. Scheller, M. Goenrich, R. Boecher, R. K. Thauer, B. Jaun, The key nickel enzyme of methanogenesis catalyses the anaerobic oxidation of methane. Nature 465, 606 (2010).

39. A. A. Prinzhofer, A. Y. Huc, Genetic and post-genetic molecular and isotopic fractionations in natural gases. Chemical Geology 126, 281 (1995).

40. F. Lorant, A. Prinzhofer, F. Behar, A.-Y. Huc, Carbon isotopic and molecular constraints on the formation and the expulsion of thermogenic hydrocarbon gases. Chemical Geology 147, 249 (1998).

41. S. Epstein, R. Buchsbaum, H. A. Lowenstam, H. C. Urey, Revised carbonate-water isotopic temperature scale. Geological Society of America Bulletin 64, 1315 (1953).

42. H. C. Urey, The thermodynamic properties of isotopic substances. Journal of the Chemical Society, 562 (1947).

43. J. M. Eiler et al., A high-resolution gas-source isotope ratio mass spectrometer. International Journal of Mass Spectrometry 335, 45 (2013). 
44. M. Lewan, Effects of thermal maturation on stable organic carbon isotopes as determined by hydrous pyrolysis of Woodford Shale. GCA 47, 1471 (1983).

45. L. C. Price, J. L. Clayton, L. L. Rumen, Organic geochemistry of the $9.6 \mathrm{~km}$ Bertha Rogers No. 1. well, Oklahoma. Org. Geochem. 3, 59 (1981).

46. D. D. Blackwell, M. Richards. (American Association of Petroleum Geologists, 2004), pp. 1 sheet, scale 1:6,500,000.

47. S. P. Dutton, "Diagenesis and burial history of the lower cretaceous travis peak formation, East Texas" (Bureau of Economic Geology Report of Investigations No. 164, 1987).

48. J. J. Sweeney, A. K. Burnham, Evaluation of a simple model of vitrinite reflectance based on chemical kinetics. AAPG Bulletin 74, 1559 (1990).

49. W. C. Torsch, Thermal and pore pressure history of the Haynesville Shale in North Louisiana: A numerical study of hydrocarbon generation, overpressure, and natural hydraulic fractures. Master's thesis, Lousiana State University (2012).

50. M. K. Roden, D. S. Miller, Apatite fission-track thermochronology of the Pennsylvania Appalachian Basin. Geomorphology 2, 39 (1989).

51. J. R. Levine, Deep burial of coal-bearing strata, Anthracite region, Pennsylvania: Sedimentation or tectonics? Geology 14, 577 (1986).

52. M. J. Johnsson, Distribution of maximum burial temperatures across northern Appalachian Basin and implications for Carboniferous sedimentation patterns. Geology 14, 384 (1986).

53. D. M. Jarvie, R. J. Hill, T. E. Ruble, R. M. Pollastro, Unconventional shale-gas systems: The Mississippian Barnett Shale of north-central Texas as one model for thermogenic shalegas assessment. AAPG bulletin 91, 475 (2007).

54. E. W. Tegelaar, R. A. Noble, Kinetics of hydrocarbon generation as a function of the molecular structure of kerogen as revealed by pyrolysis-gas chromatography. Org. Geochem. 22, 543 (1994).

55. F. R. Ettensohn, The Catskill delta complex and the Acadian orogeny: A model. The Catskill delta: Geological Society of America Special Paper 201, 39 (1985).

56. R. M. D. Matos, The northeast Brazilian rift system. Tectonics 11, 766 (1992).

57. E. V. dos Santos Neto, J. M. Hayes, Use of hydrogen and carbon stable isotopes characterizing oils from the Potiguar Basin (onshore), Northeastern Brazil. AAPG bulletin 83, 496 (1999).

58. A. Martini et al., Genetic and temporal relations between formation waters and biogenic methane: Upper Devonian Antrim Shale, Michigan Basin, USA. GCA 62, 1699 (1998).

59. J. M. Eiler, E. Schauble, ${ }^{18} \mathrm{O}^{13} \mathrm{C}^{16} \mathrm{O}$ in Earth's atmosphere. GCA 68, 4767 (2004).

60. GOR. (GeoIsochem Corp., Version 2.3.9).

61. E. P. Reeves, J. S. Seewald, S. P. Sylva, Hydrogen isotope exchange between n-alkanes and water under hydrothermal conditions. GCA 77, 582 (2012).

62. M. Lewan, J. Winters, J. McDonald, Generation of oil-like pyrolyzates from organic-rich shales. Science 203, 897 (1979).

63. M. Lewan, M. Kotarba, D. Więcław, A. Piestrzyński, Evaluating transition-metal catalysis in gas generation from the Permian Kupferschiefer by hydrous pyrolysis. GCA 72, 4069 (2008). 
332 Acknowledgements: This work was supported by the NSF, Petrobras, ExxonMobil, and

333 Caltech. We thank Petrobras and ExxonMobil for providing samples and permission to publish

334 and C. Araújo and B. Peterson for helpful discussions. Any use of trade, firm, or product names

335 is for descriptive purposes only and does not imply endorsement by the U.S. Government. All

336 data used to support the conclusions in this manuscript are provided in the Supplementary

337 Materials.

338 


\section{Figures:}

340 Fig. 1: Comparisons of $\Delta_{18}$ temperatures to environmental/formation temperatures. A)

341 Formation/reservoir temperatures vs. $\Delta_{18}$ values. The dashed line is the theoretical dependence of

$342 \Delta_{18}$ on temperature (19). Equilibrated gas data are from (19). Temperatures are

343 formation/equilibration temperatures for the pyrolysis and equilibrated samples and current

344 reservoir temperatures for the Haynesville Shale and Gulf of Mexico samples. B) Current

345 reservoir temperatures vs. $\Delta_{18}$ temperatures for all natural samples investigated except the

346 Antrim Shale samples, which are excluded because they are a mixture of thermogenic and

347 biogenic gases. The dotted line is a 1:1 line. Uncertainty for well temperatures is estimated to be $348 \sim \pm 10^{\circ} \mathrm{C}$. Error bars are $1 \sigma$.

350 Fig. $2: \delta^{13} \mathrm{C}$ values vs. $\Delta_{18}$ temperatures for methane from the Potiguar Basin. A positive 351 correlation ( $p$-value $=0.008)$ is observed. The gray band is the $95 \%$ confidence interval for the 352 linear regression through the data. Error bars are $1 \sigma$.

354 Fig. 3: Comparison of modeled methane formation temperatures for the Potiguar Basin samples $355(10,15,20,23,27,39,40)$ to $\Delta_{18}$ temperatures. Blue lines indicate gases generated from kerogen 356 breakdown, purple from oil breakdown, red from bitumen breakdown, and green the measured 357 range of $\Delta_{18}$ temperatures from the Potiguar Basin. 


\section{Supplementary Materials}

360 Materials and Methods

361 Supplementary Text

362 Figs. S1 to S5

363 Tables S1 to S6

364 References (41-63) 